\title{
The Potential Application of some Aromatic Plants Essential Oils as Natural Cosmetic Preservatives against some Bacteria in Egypt
}

\author{
M.I. Abou-Dobara, A.A. El-Fallal, A.K. El-Sayed, N.S. El-Reedy* \\ Botany Department, Faculty of Science, Damietta University, Egypt
}

Received: 21 April 2012 / Accepted: 05 June 2013

*Corresponding author (Tel: +20.012 0417 1136; Fax: +20.57.2403868, email: nesmaelreedy@ gmail.com)

\begin{abstract}
Seven undiluted essential oils (Tea tree oil, Eucalyptus oil, Lavender oil, Chamomile oil, Camphor oil, Peppermint oil and Orange oil) were investigated for their antimicrobial activity against bacteria previously isolated from face moisturizing cream samples of different brands in Egypt. All of the tested essential oils exhibited antimicrobial activity against Gram positive bacteria (Bacillus licheniformis, Bacillus subtilis, Bacillus cereus, Lactobacillus fermenti, Listeria sp, Micrococcus luteus, Micrococcus sp, Staphylococcus epidermidis, Staphylococcus aureus) and against Gram negative bacteria (Klebsiella oxytoca and Pseudomonas putida). Filter paper disc and agar diffusion well methods were used for screening the susceptibility. The results obtained indicated significance differentiation between the two methods. Essential oils of Tea tree oil, Eucalyptus oil, Lavender oil and Peppermint oil were more effective than that of Orange. On the other hand, Chamomile and Camphor oils were partially effective against tested bacteria. Minimum inhibitory concentrations (MIC) of the strongest oils were ranged from $0.08 \%$ of eucalyptus oil against bacillus subtilis to $2 \%$ of orange oil against listeria sp. Minimum bactericidal concentrations (MBC) were also measured.
\end{abstract}

Keywords: antimicrobial activity, cosmetic contamination, essential oils, minimum inhibitory concentration

\section{Introduction}

Skin-care products (especially facial creams) are the general category of cosmetic products which very important in daily routine. Cosmetics with high water content like creams are at a risk of being contaminated by microorganisms. These microorganisms can alter the composition of the product or pose a health risk to the consumer. So, cosmetic products need very good preservation, first of all in order to protect the consumer against potential dangers arising from pathogens.
Secondly, to guarantee long-term stability (shelf life) of the formula under used conditions (open jar). On the other hand, Chemicals which are highly active against microbes also have similar effects against mammalian cells especially the antifungal agents. Therefore, a balance needs to be established with the preservatives to kill the organisms and not injuring the cells of consumers who uses the product.

Parabens (most frequently methyl paraben, propyl paraben, butyl paraben) are perhaps the most widely used preservatives in cosmetic 
products due to their low cost and ease of use. Unfortunately, these chemicals are more dangerous for consumers [1]. They are associated with breast cancer and have Xenoestrogenic activity. They may play a role in DNA damage like retinols. Some parabens can interact with sunlight resulting in DNA damage. Combinations of it with benzoic acid produce high toxicity.

So, it is very important to find alternative safe and natural preservatives. Particular interest has been focused on the potential applications of plant essential oils. The major functional-group class of these compounds has the ability to inhibit the microbial growth [2]. They are extremely complex mixtures compounds including alkaloids, flavonoids, isoflavonoids, tannins, cumarins, glycosides, terpens, phenyl propannes and organic acids [3]. The oils were isolated by distillation (steam, water, fractional and hydro diffusion) and extraction. Only certain parts, such as roots, buds, leaves, or flower petals, are used. The antimicrobial properties of plant essential oils are well established against wide spectra of microbes including bacteria [4], yeasts [5] and fungi [6]. In this study, we investigated the possibility of potential application of (Tea tree, Eucalyptus, Lavender, Chamomile, Camphor, Peppermint and Orange essential oils) as natural preservatives in cosmetic face moisturizing creams.

\section{Materials and methods}

\section{Microbial strains used}

Bacterial strains (Gram positive bacteria [Bacillus licheniformis, Bacillus subtilis, Bacillus cereus, Lactobacillus fermenti, Listeria spp, Micrococcus luteus, Micrococcus spp, Staphylococcus epidermidis, Staphylococcus aureus] and Gram negative bacteria [Klebsiella oxytoca and Pseudomonas putida]) were previously isolated from face moisturizing cream samples and identified by standard microbiological methods [7].

\section{Inoculum preparation}

The bacterial isolates were cultured overnight at $37^{\circ} \mathrm{C}$ on Mueller Hinton agar. Colonies were collected from 24 hours old bacterial culture and diluted in sterile nutrient broth media by serial dilution method to prepare standardized inocula $\left(1.0 \times 10^{6} \mathrm{CFU} \mathrm{ml}^{-1}\right)$.

\section{Essential oils used}

Seven undiluted commercial Essential oils (as listed in Table1) (obtained from karma company for oils and fragrant, Cairo, Egypt) were tested for their antimicrobial activity.

Table 1. Tested essential oils

\begin{tabular}{lll}
\hline English name & Scientific name & Family \\
\hline Camphore oil & $\begin{array}{l}\text { Cinnamomum } \\
\text { camphora } \\
\text { Matricaria } \\
\text { Chamomilla }\end{array}$ & Lauraceae \\
Composite oilae \\
Peppermint oil & $\begin{array}{l}\text { Mentha } \\
\text { piperita } \\
\text { Melaleuca } \\
\text { alternifolia }\end{array}$ & Labiatae \\
Lavendula & Myrtaceae \\
Lavender oil & $\begin{array}{l}\text { Lamiaceae } \\
\text { Eucalyptus } \\
\text { Elobules } \\
\text { Citrus } \\
\text { aurantium }\end{array}$ & Myrtacea \\
Orange oil & Rutaceae \\
\hline
\end{tabular}

Evaluation of antimicrobial activity of seven essential oils towards microbes isolated from cream samples

\section{Filter paper disc method}

Filter paper disc method procedure [8] was used. Briefly, each isolate prepared as a standardized inocula (by serial dilution method), $0.1 \mathrm{ml}$ was inoculated on the surface of Mueller Hinton agar plates. A required number of filter paper discs loaded with $30 \mu \mathrm{l}$ of each essential oil $(10 \mathrm{~mm}$ diameter) were applied to the surface of previously inoculated prepared plates of Mueller Hinton agar with the tested bacteria in sterile Petri dishes (9 $\mathrm{cm}$ diameter). The plates were incubated at $37^{\circ} \mathrm{C}$ for 24 hours. The diameter of inhibition zone was measured in millimeters. A positive control in the form of methyl paraben (standard cosmetics preservative $30 \mu \mathrm{g}$ ) while sterile dry filter paper discs without essential oil were considered as negative controls.

\section{Agar diffusion well assay}

Agar well diffusion method [9] was used. Briefly, each bacterium was prepared as above, $(100 \mu \mathrm{l})$ of standardized inocula $\left(10^{6} \mathrm{CFU} \mathrm{ml}{ }^{-1}\right)$ of each test bacterium was spread onto sterile nutrient agar medium and on Mueller Hinton agar so as to 
achieve confluent growth. The plates were allowed to dry and a sterile cork borer $(5 \mathrm{~mm}$ diameter) was used to bore wells in the agar. Subsequently, a $100 \mu \mathrm{l}$ volume of the oil was introduced in wells of the agar plates. Plates without oil were used as a negative control while a positive control in the form of methyl paraben (standard cosmetics preservative) was also included in the study. The plates were allowed to stand for at least $1 \mathrm{~h}$ for diffusion to take place and then incubated at The plates were observed after $24 \mathrm{~h}$ at $37^{\circ} \mathrm{C}$. The antibacterial activity was expressed as the mean of the zone of inhibition diameters $(\mathrm{mm})$. Tests were performed in triplicate. All results analyzed for statistical significance. The results were expressed in terms of the diameter of the inhibition zone(in $\mathrm{mm}$ ): $<9$ $\mathrm{mm}$, inactive; $9-12 \mathrm{~mm}$, partially active; $13-18$ $\mathrm{mm}$, active; $>18 \mathrm{~mm}$, very active [10].

\section{Determination of $M I C$ and $M B C$}

The Minimum Inhibitory Concentration (MIC) and minimum bactericidal concentration (MBC) were determined by using the broth microdilution method on Mueller Hinton broth [11] with addition of $0.05 \%$ tween 80 to enhance the solubility of the oils in the medium, to achieve the wanted concentrations ranging from $0.05 \%$ to $4 \%(\mathrm{v} / \mathrm{v}), 100 \mu \mathrm{l}$ volume of each dilution were mixed with bacterial inoculums suspension $(1.0 \times$ $10^{6} \mathrm{CFU} \mathrm{ml}{ }^{-1}$ ).

Positive and negative growth controls were prepared. The plates were incubated for 24 hours, at $37^{\circ} \mathrm{C}$. After incubation the last tube without any visible growth of the bacteria was taken to represent the minimum inhibitory concentration (MIC). All samples showing no turbidity were sub-cultured but the lowest concentration, from which the microorganisms did not recover, was the minimal bactericidal concentration (MBC).the minimal inhibitory concentration (MIC) was defined as the lowest concentration (highest dilution) of the herbal essential oils that inhibited the visible growth (no turbidity) [12] . All dilutions were performed in duplicate. Control samples (positive and negative) were incubated under the same conditions. Optical density of each well was measured at a wavelength of $600 \mathrm{~nm}$ by spectrophotometer and compared with a blank and the positive control which was normal growth without oil.

\section{Practical application of effective essential oils on cream samples microbes}

Laboratory prepared $20 \mathrm{~g}$ of face cream samples from Reedy group cosmetic company in $250 \mathrm{ml}$ flasks preserved by each oil (eucalyptus, lavender, tea tree and mixture of lavender and tea tree oils) with concentration $0.4 \%$ ( as standard preservative concentration in creams). Equal inocula of each sample tested by spread plate counting on modified letheen agar after $48 \mathrm{hr}$ and repeated other inocula after one month and after six month under aseptic conditions closed flasks at room temperature.

\section{Statistical Analysis}

The two-tailed student's $t$-test was used to determine the statistical significance of differences observed between zones of inhibition as results of the two method and between the use of different media in the same method (agar diffusion hole assay) to determine if there were any significant differences between the media used; zones of inhibition recorded from the plates were compared using a one-way analysis of variance (ANOVA) $(P \leq 0.05)[13]$.

\section{Results}

In this study, both filter paper disc method and agar diffusion well method showed different inhibition zones and different diffusion of essential oils in the media. The effectiveness of essential oils was confirmed and growth inhibitions zone diameters were measured. Results are presented in (Table 2, 3 and 4). The inhibition zones were obtained by using filter paper disc assay in (Table 2) showed that four essential oils (eucalyptus, tea tree, peppermint and lavender oils) possessed the highest antimicrobial activity followed by orange oil. Tea tree oil is the sole oil that had an inhibition effect on all tested bacteria.

The largest inhibition zone diameter $(59 \mathrm{~mm})$ against $B$. subtilis was achieved by Eucalyptus oil which had no effect on growth of pseudomonas putida. It has the same inhibition zones $55 \mathrm{~mm}$ against both Listeria $s p$ and Micrococcus leutus. There was no growth inhibition for lavender oil against both Staphylococcus epidermidis and Pseudomonas putida. 
Table 2. Antimicrobial activity of some essential oils using filter paper method on Mueller Hinton agar media (MHA) showing the inhibition zone expressed on $(\mathrm{mm})$ for bacteria, triplicates were made

\begin{tabular}{|c|c|c|c|c|c|c|c|}
\hline \multirow[t]{2}{*}{ Bacteria } & \multicolumn{6}{|c|}{ Essential oils } & \multirow[b]{2}{*}{ CAR } \\
\hline & $\overline{E U}$ & TT & LAV & PEP & ORA & CAM & \\
\hline Bacillus subtilis & $59.0 \pm 0.57$ & $40.6 \pm 0.33$ & $53.0 \pm 0.57$ & $36.0 \pm 0.33$ & $39.0 \pm 0.33$ & $20.0 \pm 0.57$ & 0.0 \\
\hline Bacillus cereus & $18.0 \pm 0.33$ & $32.0 \pm 0.28$ & $36.0 \pm 0.33$ & $55.0 \pm 0.57$ & $32.0 \pm 0.57$ & $19.0 \pm 0.57$ & $11.6 \pm 0.33$ \\
\hline Bacillus lichenoformis & $20.0 \pm 0.33$ & $18.0 \pm 0.33$ & $13.0 \pm 0.33$ & 0.0 & 0.0 & 0.0 & 0.0 \\
\hline Lactobacillus fermenti & $36.0 \pm 0.57$ & $31.0 \pm 0.57$ & $37.0 \pm 0.33$ & $42.0 \pm 0.28$ & $19.0 \pm 0.28$ & $13.0 \pm 0.33$ & 0.0 \\
\hline Listeria sp & $37.0 \pm 0.74$ & $55.0 \pm 0.33$ & $53.0 \pm 0.57$ & 0.0 & $52.0 \pm 0.57$ & $12.0 \pm 0.33$ & $13.0 \pm 0.33$ \\
\hline Micrococcus sp & $16.0 \pm 0.57$ & $19.3 \pm 0.33$ & $18.0 \pm 0.33$ & $14.0 \pm 0.28$ & $13.6 \pm 0.33$ & 0.0 & 0.0 \\
\hline Micrococcus leutus & $53.0 \pm 0.57$ & $55.0 \pm 0.33$ & $53.0 \pm 0.57$ & $52.0 \pm 0.57$ & $20.0 \pm 0.57$ & 0.0 & 0.0 \\
\hline Staphylococcus aureus & $20.0 \pm 0.57$ & $43.0 \pm 0.57$ & $27.0 \pm 0.33$ & $22.0 \pm 0.57$ & $25.0 \pm 0.33$ & $15.0 \pm 0.57$ & $12.6 \pm 0.33$ \\
\hline Staphylococcus epidermidis & $26.0 \pm 0.33$ & $22.0 \pm 0.57$ & 0.0 & $24.0 \pm 0.28$ & $39.0 \pm 0.28$ & 0.0 & 0.0 \\
\hline Pseudomonas putida & 0.0 & $29.0 \pm 0.28$ & 0.0 & $36.0 \pm 0.33$ & 0.0 & $24.0 \pm 0.28$ & 0.0 \\
\hline Kelebsiella oxytoca & $30 \pm 0.33$ & $28 \pm 0.57$ & $16 \pm 0.57$ & $18 \pm 0.33$ & 0.0 & 0.0 & 0.0 \\
\hline
\end{tabular}

(0.0); no inhibition zone . Values (Mean of triplicate tests). EU= Eucalyptus oil, CAM= Chamomile oil, TT= Tea Tree oil, LAV= Lavender oil, ORA= Orange oil, PEP= Peppermint oil and CAR=Camphor oil.

Table 3. Antimicrobial activity of some essential oils using hole agar diffusion method on nutrient agar media showing the inhibition zone expressed on $(\mathrm{mm})$ for bacteria, triplicates were made

\begin{tabular}{|c|c|c|c|c|c|c|c|}
\hline \multirow[t]{2}{*}{ Bacteria } & \multicolumn{6}{|c|}{ Essential oils } & \multirow[b]{2}{*}{ CAR } \\
\hline & $\overline{\mathrm{EU}}$ & TT & LAV & PEP & ORA & CAM & \\
\hline Bacillus subtilis & $90.0 \pm 0.28$ & $82.0 \pm 0.33$ & $90.0 \pm 0.28$ & $40.6 \pm 0.33$ & $42.0 \pm 0.28$ & $26.0 \pm 0.28$ & $12.0 \pm 0.57$ \\
\hline Bacillus cereus & $38.0 \pm 0.28$ & $80.0 \pm 0.33$ & $80.0 \pm 0.33$ & $90.0 \pm 0.28$ & $73.0 \pm 0.33$ & $20.0 \pm 0.57$ & $13.0 \pm 0.57$ \\
\hline Bacillus lichenoformis & $29.0 \pm 0.28$ & $20.0 \pm 0.57$ & $15.0 \pm 0.57$ & $11.0 \pm 0.57$ & 0.0 & 0.0 & 0.0 \\
\hline Lactobacillus fermenti & $45.0 \pm 0.57$ & $28.0 \pm 0.28$ & $53.0 \pm 0.57$ & $69.0 \pm 0.33$ & $13.0 \pm 0.57$ & $21.0 \pm 0.57$ & 0.0 \\
\hline Micrococcus sp & $40.0 \pm 0.28$ & $63.0 \pm 0.28$ & $38.0 \pm 0.33$ & $90.0 \pm 0.28$ & $13.0 \pm 0.57$ & $11.0 \pm 0.57$ & 12.0 \\
\hline Micrococcus leutus & $63.0 \pm 0.28$ & $90.0 \pm 0.28$ & $90.0 \pm 0.28$ & $90.0 \pm 0.28$ & $13.0 \pm 0.57$ & $11.0 \pm 0.57$ & 0.0 \\
\hline Staphylococcus aureus & $38.0 \pm 0.28$ & $65.0 \pm 0.28$ & $60.0 \pm 0.28$ & $62.0 \pm 0.28$ & $20.0 \pm 0.57$ & $19.0 \pm 0.33$ & $15.0 \pm 0.57$ \\
\hline Staphylococcus epidermidis & $31.0 \pm 0.28$ & $28.0 \pm 0.57$ & $14.0 \pm 0.33$ & $30.0 \pm 0.57$ & $35.0 \pm 0.28$ & 0.0 & 0.0 \\
\hline Pseudomonas putida & $7.0 \pm 0.57$ & $45.0 \pm 0.28$ & $19.0 \pm 0.33$ & $70.0 \pm 0.28$ & $10.0 \pm 0.33$ & $20.0 \pm 0.57$ & $9.0 \pm 0.57$ \\
\hline Kelebsiella oxytoca & $39.0 \pm 0.33$ & $31.0 \pm 0.57$ & $25.0 \pm 0.28$ & $14.0 \pm 0.33$ & 0.0 & 0.0 & 0.0 \\
\hline Listeria $\mathrm{sp}$ & $90.0 \pm 0.28$ & $90.0 \pm 0.28$ & $72.0 \pm 0.28$ & $9.0 \pm 0.57$ & $25.0 \pm 0.33$ & $33.0 \pm 0.28$ & $16.0 \pm 0.33$ \\
\hline
\end{tabular}

(0.0), no inhibition, 90; complete growth inhibition.

Table 4. Antimicrobial activity of some essential oils using hole agar diffusion method on Mueller Hinton agar (MHA) media showing the inhibition zone expressed on $(\mathrm{mm})$ for bacteria, triplicates were made

\begin{tabular}{|c|c|c|c|c|c|c|c|}
\hline \multirow[t]{2}{*}{ Bacteria } & \multicolumn{6}{|c|}{ Essential oils } & \multirow[b]{2}{*}{ CAR } \\
\hline & $\overline{\mathrm{EU}}$ & TT & LAV & PEP & ORA & CAM & \\
\hline Bacillus subtilis & $90.0 \pm 0.28$ & $78.0 \pm 0.33$ & $90.0 \pm 0.28$ & $37.0 \pm 0.28$ & $41.0 \pm 0.57$ & $26.0 \pm 0.28$ & $12.0 \pm 0.57$ \\
\hline Bacillus cereus & $35.0 \pm 0.28$ & $78.0 \pm 0.33$ & $80.0 \pm 0.33$ & $90.0 \pm 0.28$ & $71.0 \pm 0.28$ & $18.0 \pm 0.57$ & $13.0 \pm 0.57$ \\
\hline Bacillus lichenoformis & $26.0 \pm 0.28$ & $20.0 \pm 0.28$ & $15.0 \pm 0.28$ & $11.0 \pm 0.28$ & 0.0 & 0.0 & 0.0 \\
\hline Lactobacillus fermenti & $42.0 \pm 0.28$ & $25.0 \pm 0.33$ & $50.0 \pm 0.28$ & $68.0 \pm 0.33$ & $12.0 \pm 0.57$ & $18.0 \pm 0.57$ & 0.0 \\
\hline Micrococcus sp & $40.0 \pm 0.57$ & $61.0 \pm 0.57$ & $35.0 \pm 0.57$ & $90.0 \pm 0.28$ & $11.0 \pm 0.57$ & $11.0 \pm 0.57$ & $10.0 \pm 0.57$ \\
\hline Micrococcus leutus & $59.0 \pm 0.57$ & $90.0 \pm 0.28$ & $90.0 \pm 0.28$ & $90.0 \pm 0.28$ & $12.0 \pm 0.57$ & $12.0 \pm 0.57$ & 0.0 \\
\hline Staphylococcus aureus & $36.0 \pm 0.33$ & $62.0 \pm 0.57$ & $60.0 \pm 0.28$ & $60.0 \pm 0.28$ & $18.0 \pm 0.33$ & $18.0 \pm 0.33$ & $14.0 \pm 0.57$ \\
\hline Staphylococcus epidermidis & $29.0 \pm 0.33$ & $25.0 \pm 0.57$ & $12.0 \pm 0.57$ & $28.0 \pm 0.57$ & $32.0 \pm 0.28$ & 0.0 & 0.0 \\
\hline Pseudomonas putida & $7.0 \pm 0.57$ & $40.0 \pm 0.57$ & $18.0 \pm 0.28$ & $68.0 \pm 0.57$ & $10.0 \pm 0.57$ & $19.0 \pm 0.57$ & $9.0 \pm 0.57$ \\
\hline Kelebsiella oxytoca & $37.0 \pm 0.28$ & $30.0 \pm 0.28$ & $23.0 \pm 0.28$ & $13.0 \pm 0.33$ & 0.0 & 0.0 & 0.0 \\
\hline Listeria sp & $90.0 \pm 0.28$ & $90.0 \pm 0.28$ & $70.0 \pm 0.57$ & $9.0 \pm 0.57$ & $22.0 \pm 0.57$ & $29.0 \pm 0.57$ & $16.0 \pm 0.33$ \\
\hline
\end{tabular}

(0.0), no inhibition, 90; complete growth inhibition.

However, orange oil caused the highest inhibition of Staphylococcus epidermidis with no effect on both $P$. putida and Bacillus lichenoformis. Peppermint oil has shown the highest inhibition zone $(55 \mathrm{~mm})$ against $B$. cereus and no antibacterial effect against both Bacillus lichenoformis and Listeria spp. Chamomile oil showed partial antimicrobial activity against 
bacterial strains. Camphor oil showed no activity against the tested bacterial strains, except slight activity against B.cereus, Staphylococcus aureus and Listeria $s p(11 \mathrm{~mm}, 12 \mathrm{~mm}$ and $13 \mathrm{~mm}$, respectively).

In agar well diffusion assay, the inhibition zones in (Tables 3 and 4) indicated that oils activity against bacteria is higher in nutrient agar media than Muller Hinton agar where Eucalyptus oil has shown $63 \mathrm{~mm}$ inhibition zone against Micrococcus leutus in nutrient agar medium and $59 \mathrm{~mm}$ in Mueller Hinton agar medium. Tea tree oil has shown larger growth inhibition zone diameters $28 \mathrm{~mm}$ in nutrient agar medium in comparison to $25 \mathrm{~mm}$ in Mueller Hinton agar medium against Staphylococcus epidermidis. While lavender oil showed the same inhibition zones in the two media $(80 \mathrm{~mm}$ and $60 \mathrm{~mm}$ ) against $B$. cereus and $S$. aureus respectively.

Effectiveness of both essential oils camphor oil and chamomile oil as antibacterial slightly increased in nutrient agar medium than in Mueller Hinton agar medium (Tables 3 and 4). Complete growth inhibition $(90 \mathrm{~mm})$ had been observed by the four strongest essential oils against some bacteria as Listeria sp, B.subtilis, $B$. cereus, Micrococcus leutus and Micrococcus sp. The MIC values of five different effective essential oils are presented in (Table 5). Essential oil has shown very high susceptibility as MIC values determined very low against bacterial strains except some strains had not detected results. The MIC value of lavender oil exhibited the lowest activity against $B$. subtilis and Micrococcus luteus $(0.1 \%)$, while it achieved $(0.66 \%$ and $1.35 \%)$ against Klebsiella oxytoca and B.licheniformis respectively. The MIC value of tea tree oil was $(0.1 \%)$ against Micrococcus luteus and listeria $s p$, while the highest MIC value $(1.35 \%)$ was recorded with $B$. subtilis (Table 5). Tea tree oil showed intermediate effect against the other tested bacteria.

The lowest MIC value (0.08\%) of Eucalyptus oil was recorded with B. subtilis (Table 5), while orange oil has shown the highest MIC value (2\%) against listeria sp. The results also showed that Lactobacillus fermenti was more sensitive to the inhibitory effect of Peppermint oil than all the other tested oils at the lowest MIC value $(0.13 \%)$. Eucalyptus oil, tea tree oil and lavender oil had the same MIC values against Micrococcus luteus $(0.1 \%)$. Similarly, MBC values of each essential oil were also determined in bacterial cultures, which were found to be higher against Klebsiella oxytoca $(3.5 \%)$, while the lower MBC values of essential oils were obtained against $B$. subtilis $(0.1 \%)$ (Table 5).

Table 5. The minimum inhibition concentrations (MICs) and the minimum bactericidal concentrations (MBCs) of five effective essential oils on tested bacteria by using broth micro-dilution method on broth Muller Hinton per percentage $\%(\mathrm{v} / \mathrm{v})$

\begin{tabular}{|c|c|c|c|c|c|c|c|c|c|c|}
\hline \multirow[t]{3}{*}{ Bacteria } & \multicolumn{10}{|c|}{ Essential oils } \\
\hline & \multicolumn{2}{|c|}{ MIC \%( v/v) } & & & & \multicolumn{3}{|c|}{$\mathrm{MBC} \%(\mathrm{v} / \mathrm{v})$} & \multirow[b]{2}{*}{ PEP } & \multirow[b]{2}{*}{ ORA } \\
\hline & $\overline{\mathrm{EU}}$ & TT & LAV & PEP & $\overline{\text { ORA }}$ & $\overline{\mathrm{EU}}$ & TT & LAV & & \\
\hline Bacillus licheniformis & 0.4 & 0.5 & 1.35 & N.D & N.D & 0.5 & 0.5 & 1.5 & N.D & N.D \\
\hline Bacillus subtilis & 0.08 & 1.35 & 0.1 & 0.16 & 0.14 & 0.1 & 1.5 & 0.15 & 0.2 & 2 \\
\hline Bacillus cereus & 0.5 & 0.18 & 0.15 & 1 & 0.18 & 1 & 2 & 2 & 1.5 & 2 \\
\hline Lactobacillus fermenti & 0.16 & 0.2 & 0.15 & 0.13 & 0.4 & 0.2 & 0.2 & 0.15 & 0.15 & 1.5 \\
\hline Listeria $\mathrm{sp}$ & 0.15 & 0.1 & 0.14 & N.D & 2 & 0.2 & 0.5 & 0.15 & N.D & 2 \\
\hline Micrococcus luteus & 0.1 & 0.1 & 0.1 & 0.14 & 0.4 & 2 & 1 & 1 & 2.5 & 3 \\
\hline Micrococcus sp & 0.7 & 0.45 & 0.5 & 1 & 1.35 & 1 & 0.5 & 0.5 & 1.5 & 1.5 \\
\hline Staphylococcus epidermis & 0.25 & 0.34 & N.D & 0.3 & 0.15 & 0.5 & 1 & N.D & 1.5 & 1 \\
\hline Staphylococcus aureus & 0.4 & 0.125 & 0.24 & 0.34 & 0.3 & 0.5 & 0.125 & 0.5 & 1 & 2 \\
\hline Klebsiella oxytoca & 0.2 & 0.23 & 0.66 & 0.5 & N.D & 3.5 & 2 & 2.5 & 3.5 & N.D \\
\hline Pseudomonas putida & N.D & 0.21 & N.D & 0.16 & N.D & N.D & 0.5 & N.D & 0.1 & N.D \\
\hline
\end{tabular}

N.D: not detected

Gram positive bacteria showed more susceptibility to essential oils than Gram negative strains. On the other hand, the most sensitive bacterium was Staphylococcus aureus and Bacillus cereus. Bacillus subtilis and Listeria spp showed very high sensitivity to eucalyptus oil than peppermint oil, while strains of Micrococcus spp and Micrococcus leutus showed very high sensitivity to peppermint oil than eucalyptus oil. Bacterial counting using spread plate technique on Petri dishes containing modified Letheen agar (MLA) were represented in (Table 6). It is 
concluded that the mixture of tea tree and lavender oil was more effective than each alone. After $48 \mathrm{hr}$ all the tested essential oils succeeded to keep bacterial counting less than $1000 \mathrm{CFU} \mathrm{g}^{-1}$ at concentration $0.4 \%(\mathrm{v} / \mathrm{w})$ (acceptable range for cosmetic cream preserving according to Federal administration of drugs (FDA) [1]). While after two periods; one month and six month the antimicrobial activity of the essential oils is reduced.

Table 6. Application of Essential oils on facial cream water in oil emulsion samples show bacterial counting by spread agar method after $48 \mathrm{hr}$ and one month and after six month at room temperature by $\mathrm{CFU} \mathrm{g}^{-1}$

\begin{tabular}{|c|c|c|c|}
\hline $\begin{array}{l}\text { Oil used } \\
0.4 \%\end{array}$ & $\begin{array}{l}\text { Bacterial } \\
\text { count } \\
48 \mathrm{~h} \\
\mathrm{CFU} \mathrm{g}{ }^{-1}\end{array}$ & $\begin{array}{l}\text { Bacterial } \\
\text { count } \\
1 \text { month } \\
\text { CFU g }\end{array}$ & $\begin{array}{l}\text { Bacterial } \\
\text { count } \\
6 \text { months } \\
\text { CFU g }^{-1}\end{array}$ \\
\hline$\overline{\mathrm{EU}}$ & $9 \times 10^{2}$ & $12 \times 10^{2}$ & $23 \times 10^{2}$ \\
\hline LAV & $7 \times 10^{2}$ & $14 \times 10^{2}$ & $32 \times 10^{2}$ \\
\hline TT & $6 \times 10^{2}$ & $11 \times 10^{2}$ & $27 \times 10^{2}$ \\
\hline PEP & $7 \times 10^{2}$ & $15 \times 10^{2}$ & $9 \times 10^{3}$ \\
\hline $\mathrm{TT}+\mathrm{LAV}$ & $3 \times 10^{2}$ & $6 \times 10^{2}$ & $15 \times 10^{2}$ \\
\hline
\end{tabular}

$\mathrm{TT}+\mathrm{LAV}$ is a mixture TT and LAV at $0.2 \%$ each

\section{Discussion}

From seven tested essential oils, four essential oils (peppermint, eucalyptus, lavender and tea tree oils) had the strongest antimicrobial effect against the tested bacteria followed by orange oil. These results resembled those obtained by Gupta et al. [21] who recorded the antimicrobial activity of eucalyptus and peppermint oils. They reported that these oils exhibited a broad range of antimicrobial activity against Staphylococcus aureus, Staphylococcus epidermidis, Bacillus subtilis, Bacillus cereus, Listeria monocytogenes, Micrococcus luteus, Klebsiella sp. They also added that peppermint oil showed higher activity against Bacillus cereus than eucalyptus oil which confirms the present result.

The essential oils had antibacterial activity against the investigated bacteria where numbers of studies prove such efficiency [22,23,24]. In addition, several studies indicated that the essential oils of the herbs belonging to family Lamiaceae like lavender oil possess biological activity against several bacteria and yeast [22]. Due to the highly antibacterial activity of eucalyptus essential oil, it is used in combination with tea tree and grapefruit essential oils to treat the malodor of necrotic ulcers [25]. The effectiveness of each essential oil was determined by filter paper disc method and inhibition zone diameters were measured. Based on growth inhibition zone diameters obtained, bacterial strains were divided into three categories; resistant $(0 \geq<12 \mathrm{~mm})$, intermediate $(12 \geq \leq 18$ $\mathrm{mm})$, and susceptible $(>18 \mathrm{~mm})$. As in the present study, inhibition zone diameters by all tested essential oils except camphor oil were obtained more than $18 \mathrm{~mm}$ which proves the susceptibility to essential oil. Similar growth inhibition zone diameters were also obtained by Prabuseenivasn et al. [26] using filter paper method, demonstrated the antibacterial activity of some plant essential oils against different bacterial strains such as Pseudomonas aeruginosa $33.3 \mathrm{~mm}, B$. subtilis $29.9 \mathrm{~mm} P$. vulgaris $29.4 \mathrm{~mm}, K$. pneumoniae $20.8 \mathrm{~mm}$ and S.aureus.

Table 7. Major constituents of tested essential oils

\begin{tabular}{|c|c|c|c|c|c|c|}
\hline Camphor & Eucalyptus & Lavender & Chamomile & Orange & Peppermint & Tea tree \\
\hline $\begin{array}{l}\text { Linalool } \\
{[14]}\end{array}$ & $\begin{array}{l}\text { 1,8-eucalyptol } \\
{[15]}\end{array}$ & $\begin{array}{l}\text { 1,5-Dimethyl- } \\
\text { 1-vinyl-4- } \\
\text { hexenylbutyrate } \\
{[16]}\end{array}$ & $\begin{array}{l}\text { alpha-bisabolol } \\
\text { [17] }\end{array}$ & $\begin{array}{l}\text { p- Octopamine } \\
\text { and p- } \\
\text { synephrine } \\
{[18]}\end{array}$ & menthol [19] & $\begin{array}{l}\text { terpinen } \\
-4-\mathrm{ol}[20]\end{array}$ \\
\hline
\end{tabular}

Ozcan et al. [27] also investigated inhibitory effects against Bacillus species (Bacillus amyloliquefaciens ATCC 3842, Bacillus brevis FMC 3, Bacillus cereus FMC 19, Bacillus megaterium DSM 32, Bacillus subtilis IMG 22, and $\mathrm{B}$. subtilis var. niger ATCC 10) using spices essential oils mainly used as preservatives in foods like thyme oil, oregano oil and mint oil, they found that mint oil has strong antibacterial activity against almost tested Bacillus strains and it is likely that essential oils of some spices may be used as antimicrobial agents to prevent the spoilage of food products. In addition, Brady et al. [28] and Ferrini et al. [29] studied the activity of tea-tree oil of Melaleuca alternifolia against clinical skin isolates of methicillin-resistant and 
sensitive Staphylococcus aureus and coagulase negative Staphylococcus aureus and found that essential oil possesses potent anti staphylococcal activity extended to strains resistant to antibiotic as confirming to results obtained in present study.

In the agar well diffusion method, eucalyptus oil has shown very high antimicrobial activity against Bacillus Subtilis which had largest inhibition zone $(90 \mathrm{~mm})$. The susceptibility of both Klebsiella oxytoca and Staphylococcus aureus were similar. In contrary, Pseudomonas putida showed resistance to the oil activity. These results were confirmed by by Trivedi et al. [30] who studied the antimicrobial activity of eucalyptus against pathogens isolated from pus of patient, the study proved that Klebsiella spp were sensitive to $5 \mu \mathrm{l}, S$. aureus to $25 \mu \mathrm{l}$ while Pseudomonas and Proteus spp required $50 \mu 1$ of eucalyptus oil and with an increasing dose of oil of eucalyptus, the resulting diameter of the zone of inhibition increased for all the organisms.

The results of the study revealed that oil of eucalyptus has antibacterial activity against Gram-positive and Gram negative bacteria. However, inhibition zone diameters obtained in both filter paper method and agar hole diffusion method have shown better antibacterial effects of essential oils against Gram-positive bacteria. Gram positive bacteria showed more susceptibility to essential oils than Gram negative strains. It may be due to volatile action of essential oils due to the absence of lipopolysaccharide layer in Gram positive bacteria that might function as an effective barrier against any incoming bio-molecule, Inouye et al. [31] and Delaquis et al. [32].

This study confirms that, although some pathogenic microorganisms are resistant to antibiotics such as some strains of staphylococcus aureus (methicillin resistance (MRSA)), there is a rare pathogen known to resist essential oils by mutating. This may well be due to the fact that bacteria are able to develop genetic mutation and resistance only against specific drug such as methicillin (beta lactam antibiotics) but their genetic system seems unable to develop defensive mutation versus many natural antibacterial terpenes, such as those found in essential oils [33, 34].

The inhibition by tested essential oils could be due to the presence of active major constituents showed in (Table 7) $[14,15,16,17,18,19,20]$ responsible for antimicrobial activity. Accordingly, differences in the activity of an essential oil to another are due to the structure activity relationship. Oils activity increased against microbes on nutrient agar media than Mueller Hinton agar due to the compounds of essential oils move easier in nutrient agar than Mueller Hinton agar (MHA) media and the component molecules for media of nutrient agar were smaller than molecules of MHA media

Other factor that should also be studied and considered is related to the diffusion ability of the tested product in the culture medium, which can favour in some situations volatile and non volatile substances. These results indicated that the five strongest essential oils had both nonvolatile and volatile antimicrobial compounds that had a high diffusion rate through nutrient agar more than MHA and the differences in media affect the response reaction of microbes and antimicrobial properties. Also, these results suggested that the two other essential oils that had weak or lack inhibitory effect on the growth may be due to low diffusion rate of these compounds through MHA media.

It appears that terpenes are made by plants as defense molecules. They are toxic to pathogens and to herbivores. They are volatile and can be released as signaling molecules, both to attract predators of pests and also to signal to pollinators [35].

Table 7 demonstrated the active ingredients of the essential oils, responsible for its various pharmacological actions and antimicrobial activity. In present study, Chamomile oil showed partial antimicrobial activity against tested bacteria with major component Alpha bisabolol. These results are similar to those obtained by McKay et al. and Janmejai et al. [36, 37]. They concluded that chamomile had moderate antimicrobial and antioxidant properties and significant antiplatelet activity, as well as preliminary results against cancer. Camphor oil in this study showed non antibacterial activity against tested bacterial strains except slight activity against Staphylococcus aureus, Listeria spp and B.cereus and those results were similar to those obtained by SimionattoI [38] who resulted that the monoterpene linalool was active only against $S$. aureus and showed inactivity against all other tested bacteria $S$. epidermidis, pseudomonas aerugenosa, B.subtilis and E.coli.

Due to the volatility properties of essential oils reduced its concentration after 6 month this would disturbed the stability of using essential oil as a preservative in creams, so their concentration should be increased up to $2 \%$ to manifest its antibacterial properties, these results were similar 
to those obtained by Kunicka-Styczynska [39] who investigated the antimicrobial activity of number of essential oils (lavender oil, tea tree oil and lemon oil) and evaluated its preserving activity against bacteria and fungi in cosmetic formulation cream indicated that essential oils reduce its microbial activity after few months by volatility, some synergistic or antagonistic effects may occur between ingredients in the products. For example, surfactants can often decrease the efficacy of the oils.

Preservative systems containing essential oils at $1 \%$ or lower were effective against $S$. aureas, Candida sp. and $A$. niger, but no combination of essential oils alone in the washing liquid was effective against $P$. aeruginosa. In present study, the combination of lavender oil and tea tree oil were more effective against most bacteria except Klebsiella oxytoca, Pseudomonas putida and Staphylococcus epidermidis. Prakash [40] also confirmed the results. They studied preservation of cosmetic compositions and obtained a clean killed of all four tested microorganisms $S$. aureus, $P$. aerugenosa, C. albicans and A. niger in 72 hour at the $2 \%(\mathrm{v} / \mathrm{w})$ level concentration of essential oils containing ( 20.00 Linalool, 5.00 Geraniol, 5.00 Lemongrass, 20.00 Bois de Rose, 20.00 Cedarwood Oil, 5.00 Marjoram Oil, 2.00 Cinnamon Bark Oil, 2.00 Cardamon Oil, 3.00 Neroli Bigarde Petals Oil, 2.00 Vanilla Resinoid, 5.00 Coriander Oil, 2.00 Oakmoss empuree, 2.00 Armoise Oil, 5.00 Menthol Crystals laevo, 2.00 Rose absolute concrete wax). These results proved that essential oils act as cosmetic preservatives wherein a cosmetic composition containing a dermatologically acceptable carrier or vehicle and certain essential oils as a preservative.

To overcome this disadvantage jars of cream should be closed after use, keep cream in small containers or in tubes with thin mouth. Bacteria like Micrococcus spp, Bacillus licheniformis, Bacillus cereus and klebsiella oxytoca which need more than $0.4 \%$ MIC of these oils were not affected.

The results of the inhibition zones yield by the activity of essential oils using agar hole diffusion method on Mueller Hinton agar and filter paper method on the same media of the four strongest oils confirm that the increase in essential oil concentration would increase its antibacterial activity giving inhibition zones for example, peppermint oil against $B$. lichenoformis and Listeria spp where this oil showed inactivity in filter paper method.
In this study, the MIC and MBC values determined where MIC reported less than $0.5 \%$ against isolated Staphylococcus aureus similar to those obtained by Carson [20] who investigated antimicrobial activity of Tea Tree Oil against some bacterial isolates like Micrococcus luteus, Micrococcus spp, Lactobacillus spp, Klebsiella spp, Staphylococcus aureus and S. epidermidis. Similar MIC values were obtaind by Delaquis [32] who investigated the antimicrobial activity of individual and mixed fractions of dill, cilantro, coriander and eucalyptus essential oils against pathogen staphylococcus aureus, Listeria monocytogenes and Lactobacillus sp. They determined the antimicrobial activities in range from $0.08 \%$ to $0.4 \%(\mathrm{v} / \mathrm{v})$ as in this study.

In comparison to results recorded by Prabuseenivasn [26] who determined the Minimum Inhibitory Concentration (MIC) of selected essential oils such as orange oil showed largest MIC values $(1.26 \%, 0.6 \%)$ against tested bacteria like $S$. aureus, B. subtilis, K. pneumonia, $P$. vulgaris, $P$. aeruginosa and $E$. coli. These results similar to results obtained from the present study where orange oil had MIC values $(0.14 \%, 0.3 \%, 1.35 \%$ and $2 \%)$ against B.subtilis , S.aureus, Micrococcus $s p$ and Listeria $s p$, respectively. Tea tree oil has shown MIC values between $(0.1 \%$ to $1.35 \%)$ compared with those concluded in Mihaliak [35] who determined that MIC values were $(0.31 \%$ and $0.08 \%)$ of E.coli and $S$. aureus respectively.

Essential oils seem to have no specific cellular targets [41]. As typical lipophiles, they pass through the cell wall and cytoplasmic membrane, disrupt the structure of their different layers of polysaccharides, fatty acids and phospholipids and permeabilize them. Cytotoxicity appears to include such membrane damage. In bacteria, the permeabilization of the membranes is associated with the loss of ions and reduction of membrane potential, collapse of the proton pump and depletion of the ATP pool $[42,43,44,45,46,47]$. Essential oils can coagulate the cytoplasm [48] and damage lipids and proteins [49,50]. Damage to the cell wall and membrane can lead to the leakage of macromolecules and to lyses [51-54].

\section{Conclusion}

Therapeutic properties of tested essential oils enhance the cosmotherapy. As a result, the addition of essential oils to cosmetic creams enhances its benefit properties for skin health and 
mood of consumers. Cosmetic and skin care industry must start using essential oils as a preservative rather than the toxic substances commonly used in making skin care creams.

\section{Acknowledgments}

This work was supported by a grant from Damietta University, Faculty of Science, Botany Department.

\section{References}

[1] http://www.fda.gov/cosmetics/productand ingredient safety/selected cosmetic ingredients/parabens.

[2] S.H.A. Naqui, M.S.Y. Khan, S.B. Vohora, Antibacterial, antifungal and anthelmintic investigation on indian medicinal plants, Fitoterapia 62 (1994) 221-228

[3] G.J.E. Nychas, natural antimicrobial from plants. In: Gould, G.W. New methods of food preservation. Londres: CRC Press (1996) 235258

[4] S.G. Deans, G. Ritchie, Antibacterial properties of plant essential oils. Int. J. Food Microbiol. 5 (1987) 165-180

[5] K.J. Lachowicz, G.P. Jones, D.R. Briggs, F.E. Bienvenu, J. Wan, A. Wilcock, M. J. Coventry, The synergistic preservative effects of the essential oils of sweet basil (Ocimum basilicum L) against acid-tolerant food microlora. Lett. Appl. Microbiol. 26 (1998) 209-214

[6] N. Paster, B.J. Juven, E. Shaaya, M. Menasherov, R. Nitzan, H. Weisslowicz, U. Ravid, Inhibitory effect of oregano and thyme essential oils on moulds and foodborne bacteria. Lett. Appl. Microbiol. 11 (1990) 33-37

[7] G.H. John, R.K. Noel, H.A. Peter Sneath, T.S. James, T.W. Stanley, Bergey's Manual of Determinative Bacteriology, ninth edition, AWaverlyCompany.1994 http://img.pdfbooks. us/289/biological_104215.jpg

[8] P.R. Murray, E.J. Baron, M.A. Pfaller, F.C. Tenver, R.H. Yolke, Manual of clinical microbiology, ASM Washington D.C. (1995)

[9] I.N. Okeke, A. Lamikanra, Bacteriological quality of skin-moisturizing creams and lotions distributed in a tropical developing country. J. Appl. Microbiol. 91 (2001) 922-928

[10] A. Junior, C. Zanil, Biological Screening of Brazilian medicinal plants. Bra. J. Sci. 95 (2000) 367-373

[11] C.F. Carson, B.D. Cookson, T.V. Riley, Susceptibility of methicillin resistant Staphylococcus aureus to the essential oils of Melaleuca alternifolia, J. Antimicrobial Chemotherapy 35 (1995) 421-424
[12] C. Thongson, P.M. Davidson, W. Mahakarrchanakul, J. Weiss, Antimicrobial activity of ultrasound assisted solvent extracted spices. Lett. App. Microbiol. 39 (2004) 401-406

[13] Spss programme for statistical analysis version 2.9

[14] Chen-Lung Ho, Eugene I-Chen Wang, YuChang Su. Essential oil Compositions and bioactivities of the various Parts of Cinnamomum camphora Sieb. var. linaloolifera Fujuta. National Chung Hsing University 31 (2009) 77 96

[15] Aihua Song, Ying Wang, Yanmei Liu. Tianjin University of Traditional Chinese Medicine, Tianjin 300193, China. Study on the chemical constituents of the essential oil of the leaves of Eucalyptus globulus Labill. Asian Journal of Traditional Medicines 4 (4) (2009)

[16] Lu Hui, Li He, Lu Huan, Li Xiao Lan, Zhou Ai Guo., Shi He Zi University, Shi He Zi city, PR China. Chemical composition of lavender essential oil and its antioxidant activity and inhibition against rhinitis-related bacteria African Journal of Microbiology 4 (2010) 309-313

[17] European Pharmacopoeia. 5th ed. Strasbourg, France: European Directorate for the Quality of Medicines of the Council of Europe (1996) 1976-1977

[18] A.M. Scott, Ph. D. Thesis. Bitter Orange (Citrus aurantium var. amara) extracts and constituents $( \pm)$-p-Synephrine and $( \pm)$-p-Octopamine National Toxicology Program (NTP), National Institute of Environmental Health Sciences (NIEHS), National Institutes of Health U.S Department of Health and Human (2004)

[19] N.R. Mhow, A. Mandsau, Department of Pharmaceutical Analysis, B.R. A review on peppermint oil. Nahata College of pharmacy, Asian Journal of Pharmaceutical and Clinical 2 (2009)

[20] C.F. Carson, T.V. Riley, RIRDC Publication No 98/70. Industries Research and Development Corporation. Antimicrobial Activity of Tea Tree Oil (1998)14-16

[21] C. Gupta, P. Amar Garg, C. Ramesh, Uniyal, Archana Kumari, Amity University, Sector-125, Noida, India Department of Microbiology. Antimicrobial activity of some herbal oils against common food-borne pathogens. African Journal of microbiology 2 (2008) 258-261

[22] A.P.L. Delamare, I.T.M. Pistorello, Liane Artico, L.A. Serafini, S. Echeverrigaray, Antibacterial activity of the essential oils of Salvia officinalis L. and Salvia triloba L. cultivated in South Brazil. Food Chemistry 100 (2007) 603-608

[23] M.L. Faleiro, M.G. Miguel, F. Ladeiro, F. Venancio, R. Tavares, J.C. Brito, A.C. Figueiredo, J.G. Barroso, L.G. Pedro, Antimicrobial activity of essential oils isolated 
from Portuguese endemic species of Thymus, Lett. Appl. Microbiol. 36 (2003) 35-40

[24] A. Fazlara, H. Najafzadeh, E. Lak, Department of basic science shahid chamran university, Iran. Pakistan journal of biological science 11 (2008) 2054-2061

[25] P.H. Warnke, H. Terheyden, Y. Acil, I. Springer, E. Sherry, Tumor smell with antibacterial essential oils. 100 (2004)

[26] S. Prabuseenivasn, M. Jayakumar, S. Ignacimuthu, In vitro antibacterial activity of some plant essential oils. BMC Complem. Altern. M. 30 (2006) 6-39

[27] M.M. Ozcan, L. Sagdic, O. Ozkan, Inhibitory effects of spice essential oils on the growth of Bacillus species. J. Med. Food 9 (2006) 418-421

[28] A. Brady, R. Loughlin, D. Gilipin, P. Kearney, M. Tunney, In vitro activity of tea-tree oil against clinical skin isolates of methicillinresistant and - sensitive Staphylococcus aureus and coagulase negative Staphylococcus aureus and as biofilms. J. Microbiol. 55 (2006) 13751380

[29] A.M. Ferrini, V. Mannoni, P. Aureli, G. Salvatore, E. Piccirilli, T. Ceddia, E. Pontieri, R. Sessa, B. Oliva, Melaleuca alternifolia essential oil possesses potent anti staphylococcal activity extended to strains resistant to antibiotic. Int. J. Immunopathol. Pharmacol. 19 (2006) 539-544

[30] N.A. Trivedi, S.C. Hotchandani, Department of Pharmacology, Medical College, Baroda 390001 , India. A study of the antimicrobial activity of eucalyptus oil. 36 (2004) 93-95

[31] S. Inouye, T. Takizawa, H. Yamaguchi, Antibacterial activity of essential oils and their major constituents against respiratory tract pathogen by gaseous contact. J. Antimicrob. Chemoth. 47 (2001) 565-573

[32] P.J. Delaquis, K. Stanich, B. Girard, G. Mazza, Antimicrobial activity of individual and mixed fractions of dill, cilantro, coriander and eucalyptus essential oils. Int. J. Food Microbiol. 74 (2002) 101-109

[33] K. Husnu Can Baser, Anadolu University, Faculty of Pharmacy Department of Pharmacognosy 26470 Eskisehir, Turkey. Presented at the Expert Group Meeting on Priority Needs of Developing Countries in the Field of MAPS held in Trieste (2011)

[34] V. Edwards-Jonesa, R. Bucka, S.G. Shawcrossa, M.M. Dawsona, K. Dunnb, Department of Biological Sciences, the Manchester Metropolitan University, Chester Street Manchester. Burns Centre, UK. The effect of essential oils on methicillin-resistant Staphylococcus aureus using a dressing model. (2004) 772-777

[35] C.A. Mihaliak, J. Gershenzo, R. Croteau, Lack of rapid monoterpene turnover in rooted plants, implication for theories of plant chemical defense. Oecologia 87 (1991) 373-376

[36] D.L. McKay, J.B. Blumberg, A review of the bioactivity and potential health benefits of chamomile tea (Matricaria recutita L.). Phytother Res 20 (2006) 519-530

[37] K. Janmejai, J.K. Srivastava, S. Gup ${ }^{\text {ta }}$ Antiproliferative and apoptotic effects 10 chamomile extract in various human cancer celıs. J. Agric. Food Chem. 55 (2007) 9470-9478

[38] E. Simionatto, C. Porto, C. Z. Stüker, I.I. Dalco, U.F. da Silva, Chemical composition and antimicrobial activity of the essential oil from Aeolanthus suaveolens. Universidade Federal de Santa Maria, Brasil (2007)

[39] A. Kunicka-Styczynska, M. Sikora, D. Kalemba, International Journal of Cosmetic Science, Lavender, tea tree and lemon oils as antimicrobials in washing liquids and soft body balms (2010) 1468- 2494

[40] C. Prakash, L. Purohit, G. Ramdeen, W. Catchpole, Aveda Corporation, United States patent documents. Preservation of cosmetic compositions .p. No. 4966754. (1990) 229-234

[41] C.F. Carson, B.J. Mee, T.V. Riley, Mechanism of action of Melaleuca alternifolia (tea tree) oil on Staphylococcus aureus determined by timekill, lysis, leakage and salt tolerance assays and electron microscopy. Antimicrob. Agents Chemother. 46 (2002) 1914-1920

[42] K. Knobloch, A. Pauli, B. Iberl, H. Weigand, N. Weis, Antibacterial and antifungal properties of essential oil components. J. Essen. Oil Res. 1 (1989) 119-128

[43] J. Sikkema, J.A.M. De Bont, B. Poolman, Interactions of cyclic hydrocarbons with biological membranes. J. Biol. Chem. 269 (1994) 8022-8028

[44] I.M. Helander, H.L. Alakomi, K. Latva-Kala, T. Mattila-Sandholm, I. Pol, E.J. Smid, L.G.M. Gorris, A. Von Wright, Characterization of the action of selected essential oil components on Gram negative bacteria. J. Agric. Food Chem. 46 (1998) 3590-3595

[45] A. Ultee, E.P. Kets, M. Alberda, F.A. Hoekstra, E.J. Smid, Adaptation of the food-borne pathogen Bacillus cereus to carvacrol. Arch. Microbiol. 174 (2000) 233-238

[46] R. Di Pasqua, G. Betts, N. Hoskins, M. Edwards, D. Ercolini, G. Mauriello, Membrane toxicity of antimicrobial compounds from essential oils. J. Agric. Food Chem. 55 (2007) 4863-4870

[47] A.V. Turina, M.V. Nolan, J.A. Zygadlo, M.A. Perillo, Natural terpenes: self-assembly and membrane partitioning. Biophys. Chem. 122 (2006) 101-113

[48] J.E. Gustafson, Y.C. Liew, S. Chew, J.L. Markham, H.C. Bell, S.G. Wyllie, J.R. Warmington, Effects of tea tree oil on 
Escherichia coli. Lett. Appl. Microbiol. 26 (1998) 194-198

[49] A. Ultee, M.H. Bennik, R. Moezelaar, The phenolic hydroxyl group of carvacrol is essential for action against the food-borne pathogen Bacillus cereus. Appl. Environ. Microbiol. 68 (2002)1561-1568

[50] S. Burt, Essential oils: their antibacterial properties and potential applications in foods. Int. J. Food Microbiol. 94 (2004) 223-253

[51] B.J. Juven, J. Kanner, F. Schved, H. Weisslowicz, Factors that interact with the antibacterial action of thyme essential oil and its active constituents. J. Appl. Bacteriol. 76 (1994) $626-631$
[52] S.D. Cox, C.M. Mann, J.L. Markham, H.C. Bell, J.E. Gustafson, J.R. Warmington, S.G. Wyllie, The mode of antimicrobial action of essential oil of Melaleuca alternifolia (tea tree oil). J. Appl. Microbiol. 88 (2000)170-175

[53] R.J.W. Lambert, P.N. Skandamis, P. Coote, G.J.E. Nychas, A study of the minimum inhibitory concentration and mode of action of oregano essential oil, thymol and carvacrol. J. Appl. Microbiol. 91 (2001) 453-462

[54] M. Oussalah, S. Caillet, S. Salmieri, L. Saucier, M. Lacroix, Antimicrobial effects of alginatebased films containing essential oils on Listeria monocytogenes and Salmonella typhimurium present in bologna and ham. J. Food Prot. 70 (2007) 901-908

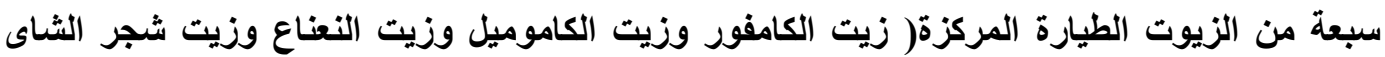

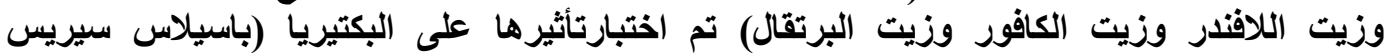

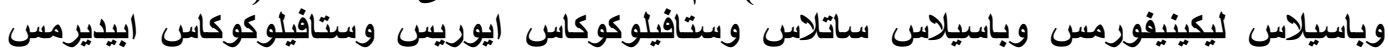

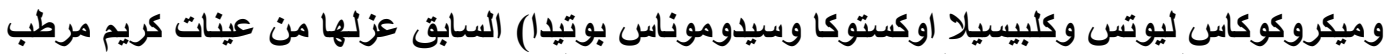

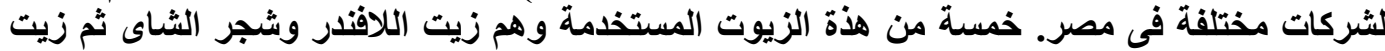

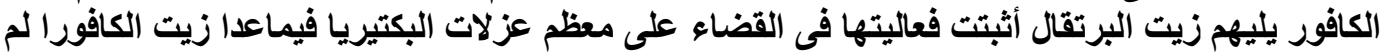

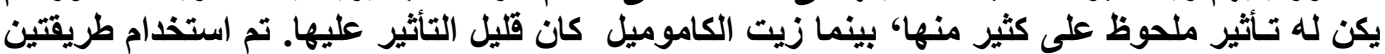

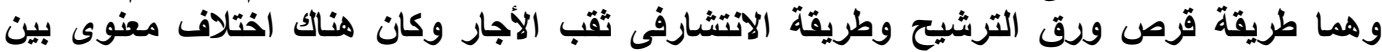

الطريقتين. من النتائج اصبح يمكن استخدام الزيوت العطرية الانتية الطيارة كمواد حافظة طبيعة لحفظ الكريمات

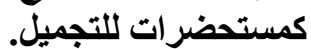

